\title{
Okul öncesi eğitim programı ile bütünleştirilmiş aile destek eğitim rehberliğinin (OBADER) annelerin çocuklarına karş1 tutumlarına etkisinin incelenmesi
}

\author{
Examination of the effects of the integrated family support education \\ guide with the preschool education program (OBADER) on the \\ attitudes of mothers towards their children
}

Esra Akosmanoğlu ${ }^{1}$, Ahmet Bedel ${ }^{2}$

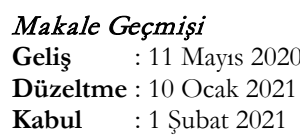

Makale Türü

Araștırma Makalesi
Article History

Received : 11 May 2020

Revised : 10 January 2021

Accepted : 1 February 2021

Article Type

Research Article
Öz: Bu çalışmanın amacı, Okul Öncesi Eğitim Programı ile Bütünleştirilmiş Aile Destek Eğitim Rehberinin (OBADER), annelerin çocuklarına karşı tutumlarına etkisini incelemektir. Araştırmada öntest-sontest kontrol gruplu yarı deneysel desen kullanılmış olup, deney grubunda 11 anne, kontrol grubunda 11 anne yer almıştır. Verilerin toplanmasında Ebeveyn Tutum Ölçeği (ETÖ) kullanılmıştır. Deney grubuna 6 haftalık eğitim programı uygulanmıș olup, kontrol grubuna herhangi bir eğitim uygulanmamıştır. Annelerin ön test son test puan farklarının anlamlılığı Mann-Whitney U-Testi ile analiz edilmiştir. Araştırma bulguları, eğitim programı sonunda annelerin demokratik tutumlarının anlamlı düzeyde arttığı, otoriter, izin verici ve koruyucu tutumlarının anlamlı düzeyde azaldığını göstermektedir. Araştırma bulgularına dayalı olarak, yorumlarda bulunulup, uygulamaya ve araştırmaya yönelik öneriler geliştirilmiştir.

Anahtar Kelimeler: Okul Öncesi, OBADER, Anne Tutumları

Abstract: The aim of this study is to examine the impact of the Integrated Family Support Education Guide with Preschool Education Program (OBADER) on the attitudes of mothers towards their children. The study used a preliminary test, final test, control group, semi-experimental pattern. There are 11 mothers in the experiment group and 11 mothers in the control group. Parental Attitude Scale is used in data collection. The experiment group participated in a 6-week training program, while no training was applied to the control group. The significance of the mothers' pre-test, post-test test differences were analyzed by the Mann-Whitney U-Test. The research findings show that the education program significantly increases mothers' democratic attitudes and significantly decreases authoritarian, permissive and overprotective attitudes. Based on the research findings, recommendations for interpretations and implementation and research have been developed.

Keywords: Preschool, OBADER, Mother Attitude 


\section{SUMMARY}

\section{Introduction}

Family is the smallest union within community, based on marriage and blood ties and being composed of relationships between wife, husband, children, and siblings (Turkish Language Association, 2020). If a child grows in a healthy family environment, he can become aware of his own potential and make it come out. Conditions formed by a healthy family environment are related with a family environment where it is avoided to have punishing approaches against the child, where the care and needs of child are met, where it is ensured that the child feels himself secured, and where safe attachment is had between the child and his mother and father (Yavuzer, 2019a). The basis of relationship between mother-father and the child is founded on the attitudes of mother and father (Yavuzer, 2016; Aktürk, 2015). The attitudes of parents also effect the personality of child (Ceylan, 2017; Yörükoğlu, 2010). Karabulut-Demir and Şendil (2008) have divided parental attitudes into four groups being Democratic attitude, authoritarian attitude, overprotective attitude and permissive attitude. Democratic attitude is the one that is most healthy and balanced among attitudes of mother and father. Their approaches toward their children are sincere, supporting and reassuring, respectful, and loving (Taner-Derman and Başal, 2013). Authoritarian attitude is the most unhealthy one among attitudes of mother and father (Sak, Şahin-Sak, Atli and Şahin, 2015). Mothers and fathers having this attitude adopt aa strict, prescriptive and punitive approach. In permissive attitude, the parent has extreme tolerance. The freedom allowed by mothers and fathers having extreme tolerance is limitless (Aydoğdu and Dilekmen, 2016). Parents having overprotective attitude protect their children from many things. They protect their children too much, they don't allow them to do anything, and they do these things in place of them. In this research, Integrated Family Support Training Guide with Preschool Education Program (OBADER) has been applied. It has been stated through researches that Integrated Family Support Training Guide with Preschool Education Program (OBADER) constitute an important factor in improving democratic attitudes of parents and in reducing their authoritarian, overprotective, and permissive attitudes. When the researches being conducted have been examined, it is seen that there is a serious limitation regarding this issue. This study bears importance with regards to mothers' gaining positive and constructive approach skills against their children, as having the most important impact on the development of their children. Ministry of National Education (2017) requests from the guidance teachers to provide information regarding the topics needed by the families and to organize training with the aim to gain necessary skills. Thus, it is expected that the results obtained from this research will provide guidance in establishing the contents of training programs to be prepared by the guidance teachers, pre-school teachers, and the experts working with the families. In this study, the impact of family support training guide being integrated with pre-school training program (Ministry of National Education, 2013) on the attitudes of mothers will be experimentally tested. The general purpose of the study is to examine the impact of Integrated Family Support Training Guide with Preschool Education Program (OBADER) on the attitudes of mothers against their children. The independent variable of the research is Integrated Family Support 
Training Guide with Preschool Education Program (OBADER) and the dependent variable of research is the attitudes of mother against her child.

\section{Method}

In this research, an unsynchronized control group model, being one of the semi-experimental models among the experimental research types has been used. Semi-experimental models are used in cases where real experimental models cannot be used (Karasar, 2019). The mothers included in this study are the mothers residing within district of Selçuklu in the city of Konya and having children aged 2-6 in the pre-school period. Mothers have been included in training based on volunteerism basis. Their children attend preschool education institutions. There are 22 mothers in total, 11 of whom are in the experimental group and 11 of whom are in the control group. Program relating with Family Support Training Guidance (OBADER) being integrated with Pre-school Training Program has been applied. A study for a period of 6 weeks has been established, whereas each session had a period of 90 minutes. Topics of the importance of preschool education, parents' attitudes, positive discipline, effective communication, games and toys, children's books were included in the sessions. Before starting with the sessions, Parental Attitude Scale was applied to the participants. Parental Attitude Scale has been developed by Karabulut-Demir and Şendil (2008) with the aim to measure the attitudes of mothers-fathers against their children aged 2-6.

\section{Results}

The findings of research show that; democratic attitudes of mothers increased at a meaningful level and their authoritarian, permissive, and overprotective attitudes got reduced at a meaningful level at the end of Integrated Family Support Training Guide with Preschool Education Program (OBADER).

\section{Conclusion and Discussion}

When the research outcomes were evaluated, it was reached to the conclusion that mother training program being applied to mothers was effective in increasing democratic attitude score of mothers and in reducing their authoritarian, overprotective and permissive attitudes. The conclusion of researches support the findings of other studies being conducted within domestic country and abroad. One of the gains obtained from training groups is that mothers observe that the problems they experience with their children are also experienced by other mothers, which helps them not to feel themselves lonely in this respect. It is considered that their observing that other members have overcome similar burdens successfully, would constitute an important particular in raising hope in them. It is thought that the specified group dynamics also have a significant contribution for attaining this result. The fact that only mothers have been included in this study constitute one of the limitations of this study. In future researches, studies can also be conducted on fathers having impact on children with regards to their attitudes. Family guidance training study can be converted into school education policy, by making it cover the parents of children in need of private education. 
Parental training can be increased in order to develop relationships of parents and children. Family training programs can also be organized in collaboration with other institutions and associations (Being within the body of Ministry of Family, Labor, and Social Services) apart from Ministry of National Education. 


\section{GİRİŞ}

Aile, evlilik ve kan bağına dayanan; karı, koca, çocuklar ve kardeşler arasındaki ilişkilerin oluşturduğu toplum içindeki en küçük birliktir (Türk Dil Kurumu, 2020). Çocuk için en sağlıklı olan yer ebeveynlerinin birlikte olduğu aile atmosferidir (Tezel-Şahin ve Özyürek, 2008). Çocuk ilk eğitimini, gelişim sürecini ailede alır ve anne baba bu süreçte çocuğa rehberlik eder (Dursun, 2010). 0-6 yaş olarak adlandırılan erken çocukluk dönemi, en kritik dönemdir. Bu önemli dönemde çocuğa ne verilirse, çocuk onu almaya hazırdır. En önemli yaşantılarını erken çocukluk döneminde yaşamaktadır. Çocuğun anne babasıyla kurduğu ilişkinin, çocuğun aile yaşantısındaki yerine etkisi bulunmaktadır (Kandır ve Alpan, 2008). Çocuk sağlıklı bir aile ortamında büyürse kendi potansiyelinin farkına varmakta ve ortaya çıkarabilmektedir (Nazlı, 2020). Sağlıklı bir aile ortamının oluşturduğu koşullar; çocuğa karşı ceza verici yaklaşımdan uzak, duyduğu ilgi ve ihtiyaçlarını karşılayan, çocuğu güvende hissettiren ve çocukla anne-baba arasında güvenli bağlanmanın gerçekleştiği aile ortamıdır (Yavuzer, 2019a). Çocuk böyle bir ailede yetişirse başkalarıyla kurduğu ilişkiler olumlu yönde gerçekleşecektir. Ailede şiddet, ilgisizlik gibi durumlar varsa çocukta kalıcı izler bırakacaktır. Sağlıksız ilişki sergileyen aileler çocuklarının ihtiyaçlarını karşılayamamakta, çocuğuyla kurduğu iletişim güvensiz, kaygllı ve korkulu olmaktadır (Gladding, 2015; Perry ve Szalavitz, 2019). Böyle bir durumda da çocuk saldırgan davranışlar sergileyip öfkesini başka kişilere yansıtacak başanısız ilişkiler gerçekleştirecektir (Çelik ve Daşcan, 2014). Aile içerisinde ebeveynler ve çocuklar birbirlerinin davranışlarını karşılıklı olarak etkilemektedir (Azkeskin, Güven, Güral ve Sezer, 2013). Çocuk ve aile arasında inşa edilen köprü, çocuğun davranışları üzerinde oldukça önemlidir (Uykan ve Akkaynak, 2019). Anne-babanın davranışları çocuğun sosyal yaşantısında olumlu ya da olumsuz davranışların oluşmasında etkili olmaktadır (Yavuzer, 2019b).

Anne-baba ve çocuk ilişkisinin temeli anne-baba tutumuna dayanmaktadır (Yavuzer, 2016; Aktürk, 2015). Ebeveyn tutumları çocuğun kişiliğini de etkilemektedir (Ceylan, 2017; Yörükoğlu, 2010). Çocuklar anne-babalarını rol model almaktadır (Cüceloğlu, 2016; Özel ve Zelyurt, 2016). Bundan dolayı benimsedikleri ebeveynlerinin tutumlarını, ileriki yaşantılarında kurdukları ailelere aktarmaktadırlar. Anne-baba tutumları toplumdan topluma, aileden aileye değişebilmektedir (Şanlı ve Öztürk, 2012). Farklı ebeveyn tutumları çocuğu farklı şekillerde etkilemektedir (Erginoğlu, 2015). Ebeveynlerin tutumlarına etki eden etmenler de vardır. Bunlar; ailenin sosyo-demografik özellikleri, ebeveynlerin yetiştirilme tarzı, ebeveynlerin çocuğun gelişimiyle ilgili bildiği şeyler, anne baba ilişkisi, çocukların kişisel özellikleridir (Çağdaş ve Şahin-Seçer, 2010; Mızrakçı, 1994; Yavuzer, 2016). Karabulut-Demir ve Şendil (2008), ebeveyn tutumlarını; demokratik tutum, otoriter tutum, aşırı koruyucu tutum ve izin verici tutum olmak üzere dört gruba ayırmıştır. 
Demokratik tutum, anne baba tutumları arasında en sağlıklı ve dengeli olanıdır. Çocuklarına karşı yaklaşımları samimi, destekleyici, güven verici, sayg1 ve sevgi çerçevesindedir (Taner-Derman ve Başal, 2013). Çocuklarından duygu ve düşünceleriyle alakalı paylaşımda bulunmalarını isterler. Çocuklarına vakit ayırırlar. Okul öncesi dönem çocuklarının bu tutumu benimseyebilmeleri için demokrasi ağırlıklı uygulamaları yaşantıya dökmek gerekmektedir (Yeşil, 2004). Demokratik tutuma sahip anne babaları olan çocukların diğer çocuklara göre daha özgüvenli, uyumlu, yaratıcı, sorumluluğunu bilen, çevresi tarafindan sevilen bireyler olduğu gözlenmiştir (Demo ve Cox, 2000; Keown ve Woodward, 2006). Otoriter tutum, anne baba tutumları arasında en sağliksız olanlarındandır (Sak, Şahin-Sak, Atli ve Şahin, 2015). Bu tutumu sergileyen anne babalar katı kuralcı ve cezalandırıcı bir yaklaşım benimserler. Çocukların verdikleri emirlere denetimleri takdirinde uymalarını isterler. Otoriter tutuma sahip ebeveynlerin çocukları saldırgan olabilmekte, özgüven eksikliği taşıyabilmekte, mutsuz ve kaygılı olabilmektedirler (Hart, Newell ve Olsen, 2003; Huntsinger ve Rose, 2009; Thompson, Hollis ve Richards, 2003). İzin verici tutumda ise, ebeveynde aşırı hoşgörü bulunmaktadır. Aşıı hoşgörülü olan anne babaların çocuklarına verdikleri özgürlügün sınırı yoktur (Aydoğdu ve Dilekmen, 2016). Çocuk mantıksız bir şey istese de yerine getirilir. Genellikle tek çocuğa sahip ailelerde tutumun görülme olasıllğı yüksektir. Ebeveynler hoşgörüyle ilgisizliği karıştırmaktadır (Özyürek, 2015). Disiplin kavramına pek rastlanamaz. Bu tutuma sahip ailesi olan çocuklar sınır tanımayan, denetim ve sorumluluk sahibi olmayan bir birey haline dönüşür. Aşırı koruyucu tutuma sahip ebeveynler çocuklarını birçok şeyden muhafaza eder. Çocuklarını fazlaca kollar, hiçbir şeyi yapmasına izin vermez onun yerine kendi yapar. Bebekleştirme bu tutumunun bir özelliğidir (Günalp, 2007). Böyle bir durumda çocuğunun gelişimini engeller (Evirgen, 2002). Așırı koruyucu tutuma sahip ebeveynlerin çocukları tek başına bir şeye karar veremeyen, kendi işini yapmakta güçlük çeken, karakterini oluşturamadığı bir dünyaya sahip olur (Cüceloğlu, 2016; Çelik ve Daşcan, 2014).

Ailelere yönelik uygulanan eğitim programlarının, annelerin çocuklarına karşı olan tutumlarını (Alkan-Ersoy, Kurtulmuş ve Çürük-Tekin, 2014; Bağatarhan ve Nazlı, 2013; Bedel, 2017; Çağdaş, 2015; Daggett, O’Brien, Zanolli ve Peyton, 2000; Kaya, 1994; Nicholson, Anderson, Fox ve Brenner, 2002; Öğretir ve Demiriz, 2009; Simpkins, Weiss, McCartney, Kreider ve Dearing 2006; Yılmaz-Bolat, 2011) olumlu yönde etkilediği sonucuna varılmıştır. Demokratik tutumlarının artmasında, otoriter, aşırı koruyucu ve izin verici tutumlarının azalmasında önemli etken olduğu araştırmalarda belirtilmiştir. (Alkan-Ersoy vd., 2014; Öğretir ve Demiriz, 2009; Tönbül, 2019; Yılmaz-Bolat, 2011). Bu eğitimler yoluyla ailelerin aile içi etkileşimlerinde pozitif davranışlarının geliştiği (Kim, Doh, Hong ve Choi, 2011), problem çözme becerilerinin arttı̆̆1 (Bracht, O'Leary, Lee ve O’Brien, 2013) görülmektedir. Thomas ve Zimmer-Gembeck (2007) çalışmasında ise, 
ebeveyn çocuk etkileşimi üzerine yapılan yirmi dört çalışmanın meta analizinde; anne çocuk etkileşim programlarının, çocukların davranışlarında olumlu etkilerini ortaya koymuştur.

Yapılan araştırmalar incelendiğinde aile eğitimlerine yönelik çalışmaların genellikle tarama modelinde yapıldığı, deneysel araştırmalarda ciddi bir kısıtlılık söz konusu olduğu görülmektedir. Bu bakımdan araştırmanın, aile rehberliğine yönelik yapılan deneysel çalışma alan yazınına katkı sağlayacağı düşünülmektedir. Bu araştırmada, Okul Öncesi Eğitim Programı ile Bütünleştirilmiş Aile Destek Eğitim Rehberi (OBADER) uygulanmıştır. OBEDER hakkında yapılan bir araştırmada ise, okul öncesi öğretmenlerinin OBADER'in yalnızca ismini bildikleri, ancak içeriği hakkında çoğunlukla bilgi sahibi olmadıkları ve eğitim ortamlarında OBADER'i yeterince kullanmadıkları belirlenmiştir (Yılmaz-Bolat, 2017). Aile eğitimlerine yönelik araştırmalar incelendiğinde OBADER'in deneysel araştırmalarda kullanımına rastlanılmamıştır. Bu araştırma, aynı zamanda OBADER'in deneysel olarak sınanmasına imkan sağlayacaktır. OBADER, ailelerin; verilen eğitimlere katılımlarını arttırma, çocuğu ile sağlıklı iletişim kurmayı sağlama, okul öncesi eğitimin önemini anlama, çocuğunun gelişim özelliklerini kavrama gibi amaçların temeliyle oluşturulan rehberlik özelliği taşıyan programdır (Milli Eğitim Bakanlığ1, 2013). OBADER'de amaç, belirlenen hedeflere yönelik etkinlikler yoluyla beceriler kazandırmaktır. OBADER, çocuklar ile sağlıklı etkileşim kurulması açısından bir kılavuz olarak büyük öneme sahiptir. Bu eğitim programında önleyici ve gelişimsel rehberlik hizmetleri yaklaşımı temel alınmıştır.

Bu çalışma, çocuklarının gelişimi üzerinde en önemli etkiye sahip olan annelerin çocuklarına karşı olumlu ve yapıcı bir yaklaşım becerisi kazanabilmeleri açısından önem taşımaktadır. Milli Eğitim Bakanlığı da (2020) rehber öğretmenlerden ailelerin ihtiyaç duydukları konularda bilgi vermelerini, gerekli becerileri kazandırmak amacıyla eğitimler düzenlemelerini istemektedir. Dolayısıyla bu araştırmadan elde edilen sonuçların rehber öğretmenlerin, okul öncesi öğretmenlerinin ve ailelerle çalışan uzmanların hazırlayacakları eğitim programlarının içeriklerinin oluşturulmasında yol göstermesi beklenmektedir. Bu çalışmada, okul öncesi eğitim programı ile bütünleştirilmiş aile destek eğitim rehberinin (Milli Eğitim Bakanlığı, 2013) anne tutumları üzerindeki etkisi deneysel olarak sinanacaktır.

Çalışmanın genel amacı, OBADER’in, annelerin çocuklarına karşı tutumlarına etkisini incelemektir. Araştırmanın bağımsız değişkeni OBADER, bağımlı değişkeni ise annenin çocuğuna karşı tutumlaridır.

Çalışmanın amacı doğrultusunda aşağıdaki araştırma sorularına yanıt aranmıştır. 
1. Deney ve kontrol grubu demokratik tutum ön test-son test fark puanları anlamlı düzeyde farklılaşmakta mıdır?

2. Deney ve kontrol grubu otoriter tutum ön test-son test fark puanları anlamlı düzeyde farklılaşmakta mıdır?

3. Deney ve kontrol grubu izin verici tutum ön test-son test fark puanları anlamlı düzeyde farklılaşmakta mıdır?

4. Deney ve kontrol grubu aşırı koruyucu tutum ön test-son test fark puanları anlamlı düzeyde farklılaşmakta mıdır?

\section{YÖNTEM}

\section{Araştırma Modeli}

$\mathrm{Bu}$ araştırmada, deneysel araştırma çeşitlerinden yarı-deneme modellerinden biri olan eşitlenmemiş kontrol gruplu model kullanılmıştır. Yarı deneysel modellerinden, gerçek deneme modellerinin kullanılamadığı durumlarda faydalanılır (Karasar, 2019). Araştırmanın geçerliliğini etkileyebileceği düşünülen faktörler dikkate alınarak veri toplama sürecine dikkat edilmiş, denek kaybının olmaması için deneklerin seçiminde ön görüşmelerde titiz davranılmış, katılanların ön test puanları, yaş ve sayı bakımından benzer nitelikte olmalarına olabildiğince özen gösterilmiştir. Deney ve kontrol gruplarının benzer nitelikte olması, yanlı gruplama olmasının önüne geçerek araştırmanın geçerliliğine katkı sağlamaktadır. Ölçeklerin uygulanması, deneysel çalışmanın başlaması ve tamamlanması arasındaki geçen süreye dikkat edilmiştir. Zaman uzadıkça, istenmedik değişkenlerin kontrol edilebilme olasılığı azalır (Karasar, 2019).

\section{Çalışma Grubu}

Bu çalışmada yer alan anneler, Konya ilinin Selçuklu ilçesinde bulunan, 2-6 yaş arası çocuğa sahip annelerdir. Anneler gönüllülük esasına göre eğitime alınmıştır. Annelerden fotoğraf, video çekimi gibi durumlarda gerekli izin alınmıştır. Katılımcıların adları ve kimliklerinin ortaya çıkmasına yol açabilecek durumlar için önlem alınmış olup, gizli tutulmuştur. Çocukları okul öncesi eğitim kurumuna gitmektedir. Deney grubunda 11, kontrol grubunda 11 olmak üzere toplam 22 anne bulunmaktadır. Tablo 1'de deney ve kontrol gruplarının demografik özelliklere ilişkin bilgiler yer almaktadır. 
Tablo 1. Araştırma gruplarının demografik özellikleri

\begin{tabular}{llllll}
\hline \multirow{2}{*}{ Değişkenler } & & $\begin{array}{l}\text { Deney } \\
\text { Frekans (f) }\end{array}$ & $\begin{array}{l}\text { Deney } \\
\text { Yüzde (\%) }\end{array}$ & $\begin{array}{l}\text { Kontrol } \\
\text { Frekans (f) }\end{array}$ & $\begin{array}{l}\text { Kontrol } \\
\text { Yüzde (\%) }\end{array}$ \\
\hline \multirow{3}{*}{ Annenin Öğrenim Durumu } & Lise & 5 & 45.5 & 7 & 63.6 \\
& Üniversite & 6 & 54.5 & 4 & 36.4 \\
& $\mathrm{~N}$ & 11 & 100.0 & 11 & 100.0 \\
\hline \multirow{3}{*}{ Annenin Çalışma Durumu } & Evet & 7 & 63.6 & 7 & 63.6 \\
& Hayır & 4 & 36.4 & 4 & 36.4 \\
& $\mathrm{~N}$ & 11 & 100.0 & 11 & 100.0 \\
\hline
\end{tabular}

Tablo 1'de demografik özelliklere ilişkin frekans dağılımları incelendiğinde; deney grubundaki annelerin \%45.5'i lise mezunu, \%54.5'i üniversite mezunudur. Ayrıca annelerin \% 63.6's1 bir işte çalışmaktadır, \%36.4’ü herhangi bir işte çalışmamaktadır. Kontrol grubuna geldiğimiz zaman annelerin \%63.6's1 lise mezunu, \%36.4'ü üniversite mezunudur. Annelerin \%63.6’s1 bir işte çalışmaktadır, \%36.4'ü çalışmamaktadır. Tablo 2'de annenin yaşı ve çocuk sayısına ilişkin bilgiler yer almaktadır.

Tablo 2. Annelerin yaşı ve çocuk sayısına ilişkin dağılım tablosu

\begin{tabular}{lllllll}
\hline & Grup & N & Ortalama & Minimum & Maximum & S \\
\hline \multirow{2}{*}{ Annenin Yaş1 } & Deney & 11 & 30.36 & 27 & 34 & 2.46 \\
& Kontrol & 11 & 30.00 & 25 & 35 & 2.72 \\
\hline \multirow{2}{*}{ Çocuk Sayıs1 } & Deney & 11 & 1.91 & 1 & 3 & 0.70 \\
& Kontrol & 11 & 1.91 & 1 & 3 & 0.70 \\
\hline
\end{tabular}

Tablo 2'de annenin yaşı ve çocuk sayısına ilişkin dağılımları incelendiğinde; deney ve kontrol grubu annelerin yaş ortalamaları 30'dur. Deney grubundaki annenin en düşük yaşı 27, en yüksek yaş1 34 tür. Kontrol grubundaki annenin en düşük yaşı 25 , en yüksek yaşı 35 'tir. Deney ve kontrol grubundaki annelerin en az 1, en çok 3 çocuğu bulunmaktadır.

\section{Veri Toplama Araçları}

\section{Ebeveyn Tutum Ölçeği (ETÖ)}

Ebeveyn Tutum Ölçeği, Karabulut-Demir ve Şendil (2008) tarafindan anne-babaların 2-6 yaş arasındaki çocuklarına karşı tutumlarını ölçmek amacıyla geliştirmişlerdir. Çocuğu 2-6 yaş arasında olan anne-babalara uygulanan ölçeğin, Demokratik (17 madde), Otoriter (11 madde), Aşırı Koruyucu ( 9 madde) ve İzin Verici (9 madde) olmak üzere 4 alt boyutu vardır. Toplamda 46 maddedir. Likert Tarzı'nda bir ölçektir. Tüm maddelerin karşısında 5 seçenek vardır. "Her zaman böyledir" 5 puan; "Çoğunlukla böyledir" 4 puan; "Bazen böyledir" 3 puan; "Nadiren böyledir" 2 puan ve "Hiçbir zaman böyle değildir" 1 puan verilmektedir. Her boyuttan alınan puanlar ayrı ayrı hesaplanarak her boyut için bir puan elde edilmektedir. Yüksek puan almak o boyutun temsil ettiği davranış şeklini benimsemek anlamına gelmektedir. Toplamda 62 maddeden oluşan ölçek geçerlik 
çalışmaları sonucu 46 maddeye düşürülmüss, 16 madde ölçekten çıkarılmıştır. Ortaya çıkan dört faktörlü yeni yapının toplam varyansın \% 33’ünü açıkladığı görülmüştür. Ebeveyn Tutum Ölçeğinin güvenirlik çalışmaları sonucu Cronbach Alfa değerleri Demokratik boyut için .83, Otoriter boyut için .76, Aşırı Koruyucu boyut için .75 ve İzin Verici boyut için ise .74' tür (Karabulut-Demir ve Şendil, 2008).

\section{Veri Toplama Süreci}

Eğitimcilerden biri, psikolojik danışman ve okul öncesi eğitim kurumu kurucusudur. Çalışma alanları arasında okul öncesinde rehberlik ve psikolojik danışma hizmetleri, aile danışmanlığ1 hizmetleri yer almaktadır. Eğitimcilerden diğerinin ise, çalışma alanları arasında psikoeğitim programları önemli yer tutmaktadır. Doktora tezini, eğitim programı yazma ve uygulama konusunda yapmıştır. Milli Eğitim Bakanlığı bünyesinde çok sayıda aile eğitimi sertifika programlanı yürütmüştür. Psikoeğitim programı uygulama konusunda çok sayıda yüksek lisans tezi ve araştırma yönetmiştir. Eğitim programına katılmak isteyen annelere davetiye ve broşür gönderilmiş olup, deney grubunda 11 ve kontrol grubu 11 anneyle eğitime başlanmıştır. Anneler 2-6 yaş arası çocuğu olan ebeveynlerden oluşmaktadır. Deney grubundaki annelere, Okul Öncesi Eğitim Programı İle Bütünleştirilmiş Aile Destek Eğitim Rehberi (OBADER) programı uygulanmıştır. Her bir oturum 90 dakika sürmesiyle birlikte 6 haftalık bir çalışma olmuştur. 6 haftalık çalışmada farklı kişiler olmak üzere 4. ve 5. oturumlarda 2'şer anne mazeretlerini bildirerek katılım sağlayamamıştır. Kontrol grubundaki annelere hiçbir müdahalede bulunulmamış, eğitim uygulanmamıştır. Sinevizyon getirilip, afiş basılıp bir oda sadece sunum şartlarına yönelik düzenlenmiştir. Oturumlarda kullanılan yöntem ve teknikler doğrultusunda gerekli araç ve gereçler kullanılmıştır. Bu araç ve gereçler şunlardır; konuşma nesnesi olan küçük bir oyuncak, büyük boy renkli kartonlar, pano, yazı tahtası, kalemler, yapısskan not kağıtları, renkli kartlar, kağıtlar, çeşitli kaşıklar, balonlar, hikaye kitapları, torba, artık materyaller (yumurta kolileri, ip, karton kutular vs.) ve oyuncaklardır. Oturumlarda kullanılan yöntem ve teknikler ise; örnek olay incelemeleri, gösteri, rol oynama, soru-cevap, grup çalışmaları, beyin firtınası, cümle tamamlama, yapışkan not kağıtları, tren, kuralı tahmin etme ve tuğla duvarıdır. Oturumlara başlamadan önce katılımcılara Ebeveyn Tutum Ölçeği uygulamıştır. Oturumlar şu şekilde düzenlenmiştir:

\section{Oturum 1: Okul Öncesi Eğitimin Önemi, Amacı ve Ailelerden Beklentiler}

1. Okul öncesi eğitiminin önemini kavrayabilme. 
Materyal: Konuşma nesnesi olan küçük bir bebek, büyük boy kağıtlar, kalın uçlu keçeli kalemler ve yapışkan not kağıtları.

Süreç: Sunuma başlamadan önce 1sınma etkinliği: "Kendimizi Tanıtmak" uygulandı. Okul öncesi eğitiminin önemi anlatılırken "Okuldan Beklentilerimiz" etkinliği uygulandı. Oturum "Afiş Hazırlayalım" değerlendirme etkinliğiyle sonlandırıldı.

\section{Oturum 2: Anne Baba Tutumları}

1. Anne-baba tutumları konusunda bilgi sahibi olabilme,

2. Olumlu anne-baba tutumunun önemini fark edebilme.

Materyal: İki farklı renk büyük boy karton, farklı davranış cümleleri yazan kağıtlar, durum kartları ve "Nasil Bir Ebeveynim” formu.

Süreç: Isınma etkinliği: “Zaman Makinesi” uygulandı ve ardından sunuma başlandı. Anne baba tutumları üzerinde duruldu. Sunumda çeşitli etkinlikler yapıldı. Bu etkinlikler sırasıyla; "Tutumları Bulalım” ve "Durum Kartları"dır. Ailelere önerilerde bulunuldu. Değerlendirme etkinliği "Nasıl Bir Ebeveynim?" formu doldurtularak oturum sonlandırıldı.

\section{Oturum 3: Olumlu Disiplin}

1. Disiplin kavramını ve disiplin ilkelerini öğrenebilme,

2. Davranış oluşturmada kurallar ve özdenetim kazandırabilme.

Materyal: Yapışkan not kağıtlanı, yazı tahtası, kalemler, kağıtlar, “Dondurma Yiyebilir miyim?” rol kağıd1, disiplin cümlelerinin olduğu kağıtlar, özdenetim kazandırmada anahtar sözcüklerin yazdığ1 dikdörtgen kesilmiş kağıtlar, çocuğa özdenetim kazandırmak için yapılması gerekenlerin yazılı olduğu kağıtlar, özdenetim kartları, soruların ve cevapların olduğu numaralı kağıtlar.

Süreç: “Kuralı Tahmin Et” 1sınma etkinliği uygulandı. Ardından sunuma başlandı. Disiplin kavramı açılandıktan sonra disiplin ilkelerinden bahsedildi. Diğer değinilen konular, çocukta olumlu davranış geliştirmede kuralların belirlenmesi ve çocuğun özdenetim kazanması oldu. Sunum esnasında sırasıyla uygulanan etkinlikler; "Ödül Çarşısı”, "Kurallar Kimin İçin”, 'Dondurma Yiyebilir miyim?”, “Birlikte Tamamlayalım”, “Özdenetimin Yapıtaşları”dır. Değerlendirme etkinliği "Oyun Kartları" ile oturum sonlandirıldı. 


\section{Oturum 4: Etkili İletişim}

1. Etkili iletişim, kabul etme, etkin dinleme ve empati kurma konularında bilgi sahibi olabilme,

2. Ben dilinin önemini kavrayabilme,

3. İletişimde karşılaşılan engelleri öğrenebilme.

Materyal: “Kim Bu?” formu, senaryo kağıdı, torba, kırmızı ve beyaz küçük kartlar, durum kartları.

Süreç: "Kim Bu?” 1sınma etkinliği uygulandı. Sunuma etkili iletişimle başlandı. Kabul etme, etkin dinleme, empati kurma konuları üzerinde duruldu. Ben dilinin önemi vurgulandı. Uygulanan etkinlikler sırası ile; “Kabul Dili”, “Can Kulağı İle Dinleyelim”, “Anla Beni”, 'Durum Kartları”dır. İletişimde karşılaşılan engellere vurgu yapıldıktan sonra değerlendirme etkinlikleri uygulandı. Bunlar; "Ben Dili" ve "İletişim Engelleri” etkinlikleridir. Bir sonraki oturum için grup üyelerinden çocuklarının giymediği eski bir çift çorabını yanlarında getirmeleri söylendi.

\section{Oturum 5: Oyun ve Oyuncaklar}

1. Oyun ve oyuncağın çocuğun gelişiminde önemini anlayabilme,

2. Oyuncak seçerken dikkat edilecek noktalar ve oyuncak güvenliği hakkında bilgilenebilme,

3. Günlük yaşamla ilişkilendirebilme.

Materyal: Artık materyaller (ip, kağıt, karton kutular, kağıt havlu ve tuvalet kağıdı ruloları, taşlar, yumurta kolileri vb.), eğitici oyuncaklar, kutu, kaşıklar (boyutları farklı tahta, metal, plastik kaşıklar), yapışkan not kağıtları ve "Oyuncak Satın Alırken Nelere Dikkat Etmeliyiz?” adlı yazılı karton.

Süreç: "Eşini Bul ve Ayağını Yerden Kes" 1sınma etkinliği uygulandı. Oyun ve oyuncağın öneminin, çocuğun gelişimine katkılarından söz edildi. Sunum aralarında yapılan etkinliklerin sırası şöyleydi; “Anne Babalar da Oynamayı Sever”, “Çocuğumla Neyi Nasıl Oynuyorum?”, "Birlikte Oynayalım”, “Kaşıklarla Ne Oynayalım?”, “Oyuncak Alıyoruz”, bir önceki oturumda grup üyelerinden istenen çorapla "Çoraplardan Ne Yapalım?”, “Kırmızı At"tır. Değerlendirme etkinliği "Misafir Oyuncaklar" uygulandı. Son oturumda uygulanacak bir etkinlik için grup üyelerinden oturuma gelirken çocuklarının en sevdiği resimli öykü kitabını getirmeleri istendi.

\section{Oturum 6: Resimli Çocuk Kitapları}

1. Resimli çocuk kitaplarının çocukların gelişimindeki önemini kavrayabilme,

2. Resimli çocuk kitaplarının özelliklerini öğrenebilme,

3. Kitap okurken dikkat edilecek noktalarını bilme, 
4. Günlük yaşamla ilişkilendirebilme.

Materyal: Renkli balonlar, asetat kalemi, resimli hikaye kitabı, resimli kartlar, farklı boyutlarda ve renklerde kağıtlar.

Süreç: "Balonumda Ne Var?” 1sınma etkinliği uyguland. Sunumda resimli kitapların çocukların gelişimine etkilerinden, resimli kitapların özelliklerinden, yaşlara göre seçiminden bahsedildi. Sunum aralarında etkinlikler uygulanmaya devam edildi. Bunlar sırası ile; "Çocukluğumuzdaki Öyküler”, "Bizim Öykülerimiz”, bir önceki oturumda grup üyelerinden istenen çocuklarının en sevdiği resimli hikaye kitabı ile "Çocuğumun Kitabı", "Bana ...... Yardım Etsin?”, "Öykü Okuyalım” etkinlikleridir. Kitap okurken dikkat edilecek noktalara değinildi. Değerlendirme etkinlikleri olan "Birlikte Katlayalım" "Kitap Torbası" uygulandı. Bu oturumla birlikte, eğitiminin sonuna gelindi. Grup lideri tarafindan oturumların özeti yapıldı. Grup üyelerinin oturumlara ve sürece ilişkin duygu ve düşünceleri alındı. Daha sonra Ebeveyn Tutum Ölçeği (ETÖ) uygulandı. Annelere Katılım Sertifikası ve hikâye kitabı hediye edilerek oturumlar sonlandırıldı.

\section{Verilerin Analizi}

Çalışma sonucunda elde edilen verilerin istatistiksel analizi için deney ve kontrol gruplarında yer alan annelerin sayılarının $(\mathrm{n}<30)$ az olması nedeniyle parametrik olmayan analizler kullanılmıstır (Büyüköztürk, 2020). Hipotez testleri sırasında ortaya çıkabilecek hataları kontrol edebilmek için, nonparametrik analizler uygulanarak, anlamlılık düzeyine dikkat edilmiştir. Deney ve kontrol grubunda olan annelere öntest-sontest yapılmıştır. Deney ve kontrol grubuna uygulanan, Ebeveyn Tutum Ölçeği puanları arasında anlamlı fark olup olmadığını anlamak için Mann-Whitney U-Testi yapılmıştır.

\section{BULGULAR}

Araştırmanın amacı, OBADER'in, annelerin çocuklarına karşı tutumlarına etkisini incelemektir. Araştırmanın sorularına yönelik bulgulara geçmeden önce Tablo 3’te deney ve kontrol grubunda yer alan annelerin ebeveyn tutum ölçeği öntest-sontest puanlarına ilişkin betimsel istatistikler gösterilmiştir.

Tablo 3. Ebeveyn tutumları ölçeği ön test son test ortalama ve standart sapma değerleri

\begin{tabular}{|c|c|c|c|c|c|}
\hline Alt Boyutlar & Grup & Ölçüm & $\mathbf{N}$ & $\overline{\mathrm{X}}$ & $\mathbf{S}$ \\
\hline \multirow{4}{*}{ Demokratik } & \multirow[b]{2}{*}{ Deney } & Ön test & \multirow[b]{2}{*}{11} & 68.55 & 5.08 \\
\hline & & Son Test & & 78.00 & 2.72 \\
\hline & \multirow{2}{*}{ Kontrol } & Ön Test & \multirow{2}{*}{11} & 67.73 & 2.05 \\
\hline & & Son Test & & 68.09 & 1.92 \\
\hline
\end{tabular}




\begin{tabular}{|c|c|c|c|c|c|}
\hline \multirow{4}{*}{ Otoriter } & \multirow{2}{*}{ Deney } & Ön test & \multirow{2}{*}{11} & 19.27 & 6.10 \\
\hline & & Son Test & & 10.55 & 4.03 \\
\hline & \multirow{2}{*}{ Kontrol } & Ön Test & \multirow{2}{*}{11} & 24.00 & 6.98 \\
\hline & & Son Test & & 23.64 & 6.86 \\
\hline \multirow{4}{*}{ Aşırı Koruyucu } & \multirow{2}{*}{ Deney } & Ön test & \multirow{2}{*}{11} & 32.82 & 5.96 \\
\hline & & Son Test & & 25.55 & 4.74 \\
\hline & \multirow{2}{*}{ Kontrol } & Ön Test & \multirow{2}{*}{11} & 29.18 & 8.55 \\
\hline & & Son Test & & 29.00 & 8.33 \\
\hline \multirow{4}{*}{ İzin Verici } & \multirow{2}{*}{ Deney } & Ön test & \multirow{2}{*}{11} & 19.36 & 3.69 \\
\hline & & Son Test & & 13.45 & 2.94 \\
\hline & \multirow{2}{*}{ Kontrol } & Ön Test & \multirow{2}{*}{11} & 20.09 & 5.20 \\
\hline & & Son Test & & 19.73 & 5.33 \\
\hline
\end{tabular}

Deney ve kontrol grubunun, ebeveyn tutumları ölçeği alt boyutları ön test puanlarının benzeşik olup olmadıkları Mann Whitney U-Testi ile analiz edilmiş ve analiz sonuçları Tablo 4’te verilmiştir.

Tablo 4. Ebeveyn tutumları ölçeği ön test puanlarına ilişkin Mann Whitney U-Testi sonuçları

\begin{tabular}{|c|c|c|c|c|c|c|}
\hline Alt Boyutlar & Grup & $\mathbf{N}$ & S1ra Ortalaması & S1ra Toplamı & $\mathbf{U}$ & $\mathbf{P}$ \\
\hline \multirow{2}{*}{ Demokratik } & Deney & 11 & 12.41 & 136.50 & \multirow{2}{*}{50.50} & \multirow{2}{*}{.509} \\
\hline & Kontrol & 11 & 10.59 & 116.50 & & \\
\hline \multirow{2}{*}{ Otoriter } & Deney & 11 & 9.45 & 104.00 & \multirow{2}{*}{38.00} & \multirow{2}{*}{.138} \\
\hline & Kontrol & 11 & 13.55 & 149.00 & & \\
\hline \multirow{2}{*}{ Aşırı Koruyucu } & Deney & 11 & 12.77 & 140.50 & \multirow{2}{*}{46.50} & \multirow{2}{*}{.356} \\
\hline & Kontrol & 11 & 10.23 & 112.50 & & \\
\hline \multirow{2}{*}{ İzin Verici } & Deney & 11 & 11.27 & 124.00 & \multirow{2}{*}{58.00} & \multirow{2}{*}{.869} \\
\hline & Kontrol & 11 & 11.73 & 129.00 & & \\
\hline
\end{tabular}

Tablo 4 incelendiğinde, deney ve kontrol gruplarının demokratik, otoriter, aşırı koruyucu ve izin verici öntest puanlarının analizleri sonucunda $(\mathrm{U}: 50.50 \mathrm{p}>.05, \mathrm{U}: 38.00$ p >.05, U:46.50 p>.05, U:58.00 p>.05) deney ve kontrol grubu arasında anlamlı bir fark olmadığı bulunmuştur.

Araştırma sorularını test etmek amacıyla son test puanlarından öntest puanları çıkarılıp, fark puanları bulunmuştur. Deney ve kontrol grubu fark puanlarının anlamlılığına bakmak için Mann Whitney U-Testi yapılmıştır (Büyüköztürk, 2016). Mann Whitney U-Testi sonuçları Tablo 5'te gösterilmiştir.

Tablo 5. Ebeveyn tutumları ölçeği ön test son test fark puanlarına ilişkin Mann Whitney U-Testi sonuçları

\begin{tabular}{|c|c|c|c|c|c|c|}
\hline Alt Boyutlar & Grup & $\mathbf{N}$ & Sira Ortalaması & Sira Toplamı & $\mathbf{U}$ & $\mathbf{P}$ \\
\hline \multirow{2}{*}{ Demokratik } & Deney & 11 & 6.18 & 68.00 & \multirow{2}{*}{2.00} & \multirow{2}{*}{.001} \\
\hline & Kontrol & 11 & 16.82 & 185.00 & & \\
\hline \multirow{2}{*}{ Otoriter } & Deney & 11 & 16.82 & 185.00 & \multirow{2}{*}{2.00} & \multirow{2}{*}{.001} \\
\hline & Kontrol & 11 & 6.18 & 68.00 & & \\
\hline \multirow{2}{*}{ Aşırı Koruyucu } & Deney & 11 & 16.32 & 179.50 & \multirow{2}{*}{7.50} & \multirow{2}{*}{.001} \\
\hline & Kontrol & 11 & 6.68 & 73.50 & & \\
\hline \multirow{2}{*}{ İzin Verici } & Deney & 11 & 16.82 & 185.00 & \multirow{2}{*}{2.00} & \multirow{2}{*}{.001} \\
\hline & Kontrol & 11 & 6.18 & 68.00 & & \\
\hline
\end{tabular}


Tablo 5 incelendiğinde, demokratik, otoriter, aşırı koruyucu ve izin verici alt boyutlarının öntest sontest fark puanları açısından deney grubu lehine anlamlı düzeyde farklılaştığı görülmektedir $(\mathrm{U}: 2.00 \mathrm{p}<.05, \mathrm{U}: 2.00 \mathrm{p}<.05, \mathrm{U}: 7.50 \mathrm{p}<.05, \mathrm{U}: 2.00 \mathrm{p}<.05)$. Bu sonuçlara göre deney grubundaki annelerin demokratik anne tutumunun artmasında ve otoriter, aşırı koruyucu, izin verici tutumlarının azalmasında uygulanan OBADER'in etkili olduğu söylenebilir.

\section{SONUÇ ve TARTIŞMA}

Araştırmanın amacı, OBADER’in, annelerin çocuklarına karşı tutumlarına etkisini incelemektir. Araştırma sonucunda elde edilen bulgularda, OBADER'in eğitime katılan annelerin tutumlarının değişmesinde etkili olduğu sonucuna varılmıştır. Araştırmalardan elde edilen bu sonuç, yurt içi ve yurt dışında yapılan diğer çalışmaların bulgularını (Alkan-Ersoy, Kurtulmuş ve Tekin, 2014; Cheng, 2004; Çağdaş, 2015; Daggett vd., 2000; Gunderson, 2004; Kaya, 1994; Maloney, 2005; Öğretir ve Demiriz 2009; Simpkins vd., 2006; Tuijl ve Leseman, 2004; Yllmaz-Bolat, 2011) destekler niteliktedir. Çocuğun gelişimi üzerindeki etkilerinden dolayı ideal ebeveyn tutumu demokratik tutumdur. Demokratik tutum; ebeveyn tutumları arasında en etkili ve başarılı olan tutumdur (Çağdaş, 2015; Yavuzer, 2019b). Annelerin demokratik tutumlarının artırılmasının eğitim yoluyla mümkün olduğu görülmektedir. Anneler bu eğitim programları sayesinde çocuklarına karşı daha yapıcı ve kabul edici davranışlar sergilemelerinin öneminin farkına vardıkları gözlenmiştir. $\mathrm{Bu}$ dönemde çocukların da en temel ihtiyaçları kendilerini güvende hissedecekleri bir ortam ve tutarlı sağlıklı bir ebeveyn tutumudur (Gladding, 2015).

Ebeveyn tutumlarının demokratik alt boyutu için elde edilen bulguda, OBADER'in eğitime katılan annelerin çocuğuna karşı olan demokratik tutumunu arttırmada etkili olduğunu göstermiştir. İlgili literatür tarandığında yapılan diğer araştırma sonuçlarında da (Bedel, 2017; Kim vd., 2011; NaikPolan, 2004; Öğretir, 2004; Simpkins vd., 2006; Temel, 1999) anne eğitiminin annelerin demokratik puanının artmasında etkili olduğu görülmektedir. Kılınç (2011) tarafından yapılan araştırmada ise, anne-çocuk etkileşim ve anne eğitim programının, annelerin çocuk yetiştirme tutumlarını anlamlı düzeyde etkilemediği sonucu elde edilmiştir. Eğitim programında gerçek yaşam durumlarında karşı karşıya kaldıkları olayların ele alınmasının, bu durumlardaki tutumlarına, yaklaşımlarına ve bakış açılarına yönelik yapılan etkinliklerinin annelerin demokratik tutumlarının artmasında etkili olduğu söylenebilir. Etkili iletişim, kabul düzeyinin artması, dinleme becerileri gibi etkinliklerin bu sonucun elde edilmesine katkı sağladığı görülmektedir. Program kazanımları, annelerin demokratik tutumu kullanarak, çocuğuyla daha sağlıklı bir iletişim kurmasına, çocuğuna karşı hoşgörülü, güven verici ve destekleyici bir yaklaşımda bulunmasına katkı sağlamaktadır. Aile eğitimlerinin, aile ve çocuk 
arasındaki etkileşimi ve iletişimi geliştirdiği, ailenin yaşam kalitesine katkı sağladığı bilinmektedir (Preece ve Trajkovski, 2017)

Araştırmanın ikinci bulgusunda, OBADER'in annelerin otoriter tutumlarını azaltmada etkili olduğu görülmektedir. İlgili literatür tarandığında yapılan çalışmalar (Demircioğlu, 2012; Nicholson vd., 2002; Tönbül, 2019) benzer sonuçlar elde edilmiştir. Annelerin, eğitim programında çocuklarıyla birlikte verimli bir zaman geçirebilmeleri için yapılan birlikte oyun oynama, birlikte kitap okuma gibi etkinliklerin onların otoriter tutumlarının azalmasında etkili olduğu söylenebilir. Çocukların okul öncesi gelişim çağından itibaren kendilerini değerli görmelerinde, yeterli hissetmelerinde ve özerk davranışlarının gelişiminde ebeveyn tutumlarının çok önemli olduğu görülmektedir. Aile eğitiminin, ailelerin disiplin anlayışını değiştirdiği ve dolayısıyla çocuklarda problem davranışların azalmasında etkili olmaktadır (Leung, Chan, Lam, Yau ve Tsang, 2016). Sabırla, sevgiyle beslenen ve sürekli olan sağlıklı ilişkiler fiziksel ve ruh sağlığının temelidir (Cüceloğlu, 2016; Perry ve Szalavitz, 2019).

Çalışmanın bir diğer bulgusunda, uygulanan OBADER'in annelerin aşırı koruyucu tutumlarını azaltmada etkili olduğu görülmektedir. Literatür tarandığında yapılan diğer araştırma sonuçları (Erkan ve Durmuşoğlu, 2006; Kaya, 1994; Fox, Duffy ve Keller, 2006; Naik-Polan, 2004) bu bulguyu destekler niteliktedir. Eğitim programında, programının bütünüyle birlikte özdenetimin yapıtaşlarına ve olumlu disiplin kazandırmaya yönelik yapılan etkinliklerin annelerin aşırı koruyucu tutumlarının azalmasında etkili olduğu söylenebilir. Annelerin demokratik tutumlarının artması ve otoriter tutumlarının azalmasının aşırı koruyucu tutumların azalmasında etkili olduğu düşünülmektedir. Aile eğitimleri, aile içi iletişimi güçlendirmekte, pozitif davranışlarının gelişimini destekleme ve disiplin anlayışını geliştirmektedir (Cüceloğlu, 2016; Kim vd., 2011; Preece ve Trajkovski, 2017).

Araştırmanın son bulgusunda, uygulanan OBADER'in annelerin izin verici tutumlarını azaltmada etkili olduğu görülmektedir. Yapılan araştırmalar (D’Aoust, 2008; Evirgen, 2002; Kağıtçıbaşı, 2007; Kaya, 1994; Temel ve Aksoy, 2000) bu bulguyu destekler niteliktedir. Bu sonucun elde edilmesinde, eğitim programında annelerin gün içerisinde yaşadıkları durumlar karşısında nasıl bir tutum sergilediklerini fark etmelerine ve hangi tutumun istedikleri gibi çocuk yetiştirmeye katkı sağlayacağına yönelik yapılan etkinliklerin etkili olduğu söylenebilir. Çocukların bu gelişim dönemlerinde ihtiyaç duydukları yaklaşım ne çok otoriter nede aşırı koruyucu ve aşırı hoşgörülü yaklaşımdır. Çocukları sağlıklı gelişimleri için ihtiyaçları olan dengeli ve demokratik bir yaklaşımdır. $\mathrm{Bu}$ yaklaşım, çocukların hem fiziksel, bilişsel, hareket, dil, sosyal ve duygusal gelişimlerinde en önemli bir faktördür (Perry ve Szalavitz, 2019; Yavuzer, 2016). 
Araştırma sonuçları değerlendirildiğinde, annelere uygulanan OBADER'in annelerin demokratik tutum puanını arttırmada; otoriter, aşırı koruyucu ve izin verici tutum puanlarını ise düşürmede etkili olduğu sonucuna varılmıstır. Eğitim gruplarının kazanımlarından birisi de, annelerin çocuklarıyla yaşadıkları sorunları diğer annelerin de yaşadıklarını görmeleri ve onların kendilerini yalnız hissetmemeleridir. Diğer üyelerin benzer sıkıntıların üstesinden başarıyla geldiklerini gözlemlemek, kendilerine umut aşılamalarında önemli bir etken olduğu düşünülmektedir. Belirtilen grup dinamiğinin de bu sonucun elde edilmesinde önemli katkısının olduğu düşünülmektedir. Aile eğitimlerinin aileyi güçlendirdiği, baş etme becerilerini geliştirdiği ve ailelerin işlevselliği üzerinde önemli bir etkiye sahip olduğu bilinmektedir (Lucksted vd., 2013; Mercado vd., 2016). Okul öncesi dönemde yapılan aile eğitimlerinin, ailenin ileriki eğitim dönemlerinde eğitim çalışmalarına katılımına katkı sağlayacağı düşünülmektedir. Ailenin eğitim faaliyetlerine katılımı, çocuğunun eğitim yaşantısına katkı sağlamaktadır (Manigo ve Allison, 2017). Bu çalışmada sadece annelerin yer alması bu çalışmanın sınıllılığından biridir. Gelecek araştırmalarda, babaların da yer aldığı çalışmalar yapılabilir. Aile rehberliği eğitimi çalışması özel eğitime gereksinimi olan çocukların ebeveynlerini de kapsayarak okul eğitim politikası haline getirilebilir. Ebeveyn çocuk ilişkilerini geliştirmek için ebeveyn eğitimleri arttırılmalıdır. Bunun için, Milli Eğitim Bakanlığı dışında da diğer kurum ve kuruluşlarla (Aile, Çalışma ve Sosyal Hizmetler Bakanlığına bağlı) işbirliği içerisinde aile eğitim programları düzenlenebilir.

\section{KAYNAKÇA}

Aktürk, F. M. (2015). Cocuklar Okul Öncesi Eğitime Devam Eden (5 Yaș Grubu) Ebeveynlerin Ana-Baba Tutumlarmm Farkh Değişkenler Açısından Incelenmesi (Yayınlanmamış yüksek lisans tezi). Selçuk Üniversitesi, Konya.

Alkan-Ersoy, Ö., Kurtulmuş, Z., \& Çürük-Tekin, N. (2014). Aile çocuk eğitim programının annelerin çocuk yetiştirme tutumlarına ve ev ortamını düzenlenmelerine etkisinin incelenmesi. Kastamonu Ë̆itim Dergisi, 22(3), 1077-1090.

Aydoğdu, F., \& Dilekmen, M. (2016). Ebeveyn tutumlarının çeşitli değişkenler açısından değerlendirilmesi. Bayburt Ë̆itim Fakültesi Dergisi, 11(2), 569-585.

Azkeskin, K., Güven, G., Güral, M., \& Sezer, T. (2013). Parenting styles: Parents with 5-6 year old children. Journal of Educational and Instructional Studies in the World, 3, 74-82.

Bağatarhan, T., \& Nazlı, S. (2013). Ebeveyn eğitim programının annelerin ebeveynlik özyeterliklerine etkisi. Sosyal Politika Çalısmalar, (31), 67-88.

Bedel, F. (2017). Anne eğitimi programınn özel gereksinimli çocuklarn annelerinin çocuk yetiștirme tutumlarna ve çocuklarryla ilişkisine etkisinin incelenmesi (Yayınlanmamış yüksek lisans tezi). Selçuk Üniversitesi, Konya. 
Bracht, M., O'Leary, L., Lee, S. K., \& O'Brien, K. (2013). Implementing family-integrated care in the NICU: A parent education and support program. Advances in Neonatal Care, 13(2), 115126.

Büyüköztürk, Ş. (2020). Sosyal bilimler için veri analiæi. Ankara: Pegem Akademi Yayıncllı.

Büyüköztürk, Ş. (2016). Deneysel desenler. Ankara: Pegem Akademi Yayıncılık.

Ceylan, Ö. (2017). Anne baba tutumlarn ile çocuğun sosyalleşme süreci arasindaki ilişki: Okul öncesi örneği (Yayınlanmamış yüksek lisans tezi). İstanbul Gelişim Üniversitesi, İstanbul.

Cheng, S. H. (2004). Factors that influence the effectiveness of a parenting program for asians and pacific uslanders (Unpublished doctoral thesis). Utah State University, Logan, Utah, USA.

Cüceloğlu, D. (2016). Geliștiren anne baba. İstanbul: Remzi Kitabevi

Çağdaş, A., \& Şahin Seçer, Z. (2010). Anne-baba eğitimi. Ankara: Kök Yayıncılık.

Çağdaş, A. (2015). Anne-baba-çocuk iletişimi. Ankara: Nobel Yayınları.

Çelik, D., \& Daşcan, Ö. (2014). Son değğsiklerle okul öncesi eğitimi programı ve etkinlik kitabı. Ankara: Anı Yayincilik.

Daggett, J. M., O’Brien, K., Zanolli, V., \& Peyton, V. (2000). Parents attitudes about children: associations with parental life histories and child rearing quality. Journal of Family Psychology, 14(2), 187-199.

D'Aoust, R. F. (2008). The impact of early childhood poverty on academic achievement and the influence of supportive parenting. (Unpublished doctoral thesis), University of Rochester, Margaret Warner School of Graduate Education, New York.

Demircioğlu, H. (2012). Altı yaşında çocuğu olan annelere uygulanan aile eğitimi programının aile işlevleri ve anne baba tutumları ile çocuğun gelissimi üzerindeki etkisinin incelenmesi (Yayınlanmamış doktora tezi). Gazi Üniversitesi, Ankara.

Demo, D., \& Cox, M. (2000). Families with young children: A review of research in the 1990s. Journal of Marriage and Family, 62, 876-895.

Dursun, A. (2010). Okul öncesi dönemdeki çocuklarm davranış problemleriyle anne-baba tutumlar arasındaki ilişkinin incelenmesi (Yayınlanmamış yüksek lisans tezi). Dokuz Eylül Üniversitesi, İzmir.

Erginoğlu, E. S. (2015). Kardess iliş̧kileri, anne-baba tutumları, davranıs ve uyum problemlerinin baž değişkenler açısından değerlendirilmesi (Yayınlanmamış yüksek lisans tezi). Ankara Üniversitesi, Ankara.

Erkan, S., \& Durmuşoğlu, M. C. (2006). Anne eğitimi programmm annenin çocuk yetiștirme tutumlarma etkisinin incelenmesi. Avrupa Birliği Sürecinde Okul Öncesi Eğitimin Geleceği Sempozyumu, İstanbul: Ya-Pa Yayın Pazarlama.

Evirgen, Ş. (2002). Okul öncesi eğitim çerçevesinde” okul destekli anne eğitim programmmn anneler üzerindeki etkilerinin incelenmesi (Yayınlanmamıs yüksek lisans tezi). Marmara Üniversitesi, İstanbul. 
Fox, R.A., Duffy K. M., Keller M.K. (2006). Training community based professionals to imlement an emprically supported parenting program. Early Child Development and Care, 176(1), 19-31.

Gladding, S. (2015). Aile Terapisi: Taribi, Kuram ve Uygulamalar (5.Baskı). (İbrahim Keklik \& İbrahim Yıldırım, çev.). Ankara: Türk Psikolojik Danışma ve Rehberlik Derneği.

Gunderson, T. (2004). The use of stres management in combination with parent training: an intervention study with parents of preschool children (Unpublished doctoral thesis). Utah State University, Logan, Utah, USA.

Günalp, A. (2007). Farklı anne baba tutumlarnm okul öncesi eğitim çağındaki çocuklarn öægüven duygusunun gelişimine etkisi (Aksaray ili örneği) (Yayınlanmamış yüksek lisans tezi). Selçuk Üniversitesi, Konya.

Hart, C. H., Newell, L. D., \& Olsen, S. (2003). Parenting skills and social-communicative competence in childhood. In J. O. Greene ve B. R. Burleson (Eds.), Handbook of communication and social interaction skills (pp. 753-797). Mahwah, NJ: Erlbaum.

Huntsinger, C. S., ve Rose, P. S. (2009). Relations among parental acceptance and control and children's social adjustment in Chinese American and European American families. Journal of Family Pyschology, 23, 321-330.

Kağıtçıbaş1, Ç. (2007). Kültürel psikoloji külttür bağlamında insan ve aile. İstanbul: Evrim Yayınevi.

Karabulut-Demir, E., \& Şendil, G. (2008). Ebeveyn tutum ölçeği (ETÖ). Türk Psikoloji Yąılar, 11(21), 15-25.

Kandır, A., \& Alpan, Y. (2008). Okul öncesi dönemde sosyal-duygusal gelişime anne-baba davranışlarının etkisi. Aile ve Toplum, 4(14), 33-38.

Karasar, N. (2019). Bilimsel araștırma yöntemi. Ankara: Nobel Akademik Yayıncıllk.

Kaya, Ö. (1994). Annelere verilen eğitimin çocuklarna karșı istenmedik tutumlarna etkisi(Yayınlanmamış yüksek lisans tezi). Gazi Üniversitesi, Ankara.

Keown, L.J., \& Woodward, L.J. (2006) "Preschool Boys with Pervasive Hyperactivity: Early Peer Functioning and Mother-Child Relationship Influences". Social Development, 15(1), 23-45.

Kilınç, F. E. (2011). Anne eğitim programı ile anne çocuk etkileşim programmm 2436 aylhk çocuklarm bilişsel becerilerine ve annelerin çocuk yetiștirme davranışlarna etkisinin incelenmesi (Yayınlanmamış doktora tezi). Selçuk Üniversitesi, Konya.

Kim, M. J., Doh, H. S., Hong, J. S., \& Choi, M. K. (2011). Social skills training and parent education programs for aggressive preschoolers and their parents in South Korea. Children and Youth Services Review, 33(6), 838-845.

Leung, C., Chan, S., Lam, T., Yau, S., \& Tsang, S. (2016). The effect of parent education program for preschool children with developmental disabilities: A randomized controlled trial. Research in Developmental Disabilities, 56, 18-28. 
Lucksted, A., Medoff, D., Burland, J., Stewart, B., Fang, L. J., Brown, C., Jones, A., Lehman, A., \& Dixon, L. B. (2013). Sustained outcomes of a peer-taught family education program on mental illness. Acta Psychiatrica Scandinavica, 127(4), 279-286.

Manigo, C., \& Allison, R. (2017). Does pre-school education matter? Understanding the lived experiences of parents and their perceptions of preschool education. Teacher Educators' Journal, 10, 5-42.

Maloney, R. (2005). Cultivating mindful parenting during marital transition: an initial evaluation of the mindful parenting program (Unpublished doctoral thesis). The University of Lowa, USA.

Mızrakç1, S.. (1994). Annelerin çocuk yetistirme tutumlarna etki eden faktörler: demografik özellikleri, kendi yetistirilis tarzlar, cocuk gelisimine iliskin bilgi düzeyleri ve cocuğun mizacma ilişkin algzlar (Yayınlanmamış yüksek lisans tezi). Ege Üniversitesi, İzmir.

Mercado, M., Fuss, A. A., Sawano, N., Gensemer, A., Brennan, W., McManus, K., Dixon, L.B., Haseldan, M., \& Cleek, A. F. (2016). Generalizability of the NAMI family-to-family education program: Evidence from an efficacy study. Psychiatric Services, 67(6), 591-593.

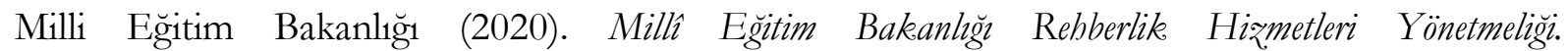
https://www.resmigazete.gov.tr/eskiler/2020/08/20200814-2.htm

Milli Eğitim Bakanlığ1 (2013). Okul öncesi eğitim programı ile bütünleştirilmiş aile destek eğitimi rehberi (OBADER). Milli Eğitim Bakanllğı Temel Eğitim Genel Müdürlüğü.

Naik-Polan, A. J. (2004). The effectiveness of a dyadic parent training intervention with high risk families: generalization to the home (Unpublished doctoral thesis). DePaul University, Chicago, Illinois, USA.

Nazlı, S. (2020). Aile danısmanliğg. Ankara: Anı Yayncılık

Nicholson, B., Anderson, M., Fox, R., \& Brenner, V. (2002). One family at a time: a prevention program for at-risk parents. Journal of Counseling \& Development, 80(3), 362-371.

Öğretir, A. D. (2004). Pozitif düş̈̈nmeye dayah grup eğitimi programınn annelerin benlik algzsı, eşlerine ve cocuklarna yönelik tutumlar ile kendini denetleme becerisi ve otomatik düsünceleri üzerinde etkisi (Yayınlanmamış doktora tezi). Ankara Üniversitesi, Ankara.

Öğretir, A. D., \& Demiriz S. (2009). Anne ev ziyareti eğitim programının annelerin tutumlarına ve empatik eğilimlerine etkisi. Ankara Üniversitesi Eğitim Bilimleri Dergisi, 42(1), 412-433.

Özel, E., \& Zelyurt, H. (2016). Anne baba eğitiminin aile çocuk ilişkilerine etkisi. Sosyal Politika Calismalarn Dergisi, 36, 9-34.

Özyürek, A. (2015). Okul öncesi çocukların sosyal beceri düzeyleri ile anne tutumları arasındaki ilişkinin incelenmesi. Millı̂ Ĕ̈itim Dergisi, 206, 106-120.

Özyürek, A., \& Tezel Şahin, F. (2020). Anne-baba olmak ve anne-babaların çocuk yetiştirme tutumları. İçinde Güler Yıldız, T. (Editör). Anne baba eğitimi (s. 41-61). Ankara: Pegem Akademi Yayıncllik. 
Perry, B. D., \& Szalavitz, M. (2019). Köpek gibi büyütülmüss çocuk. (Ed. Zübeyde Abat; Çev. Belgin Selen Haktanır). İstanbul: Koridor Yayınc1lı.

Preece, D., \& Trajkovski, V. (2017). Parent education in autism spectrum disorder- a review of the literature. Hrvatska revija za rehabilitacijska istraživanja, 53(1), 128-138.

Sak, R., Şahin Sak, İ. T., Atli, S., \& Șahin, B. K. (2015). Okul öncesi dönem: Anne-baba tutumları. Mersin Üniversitesi Eğitim Fakültesi Dergisi, 11(3), 972-991.

Simpkins, S. D., Weiss, H. B., McCartney, K., Kreider, H. M., \& Dearing, E. (2006). Mother- child relationship as a moderator of the relation between family educational involvement and child achievement. Parenting: Science and Practice. 6(1), 49-57.

Şanlı, D., \& Öztürk, C. (2012). Annelerin çocuk yetiştirme tutumlarını etkileyen etmenlerin incelenmesi. Buca Eğitim Fakültesi Dergisi, (32), 31-48.

Taner-Derman, M., \& Başal, H. A. (2013). Okul öncesi çocuklarında gözlenen davranış problemleri ile ailelerinin anne-baba tutumları arasındaki ilisski. Amasya Üniversitesi Ë̆itim Fakültesi Dergisi 2(1), 115-144.

Temel, Z. F.(1999, Jully, 30). The study of the effect of mother-child education program. International school psychology association XXII annual coolquim theme and scientific program. Kreuzlingen/konstanz, Switzerland) Germany.

Temel, Z. F., \& Aksoy, A. B. (2000). Home-based mother training program for 0-3 years of age and its effects on home environment. Psychologie \& Education, 25/26(1-2), 51-57.

Tezel-Şahin, F., \& Özyürek, A. (2008). 5-6 yaş grubu çocuğa sahip ebeveynlerin demografik özelliklerinin çocuk yetiștirme tutumlarına etkisinin incelenmesi. Türk Ë̆itim Bilimleri Dergisi, 6(3), 395-414

Thompson, A., Hollis, C., ve Richards, D. (2003). Authoritarian parenting attitudes as a risk for conduct problems: Results from a British national cohort study. European Child \& Adolescent Psychiatry, 12, 84-91.

Thomas, R., \& Zimber-Gembeck, M. J. (2007). Behavioral outcomes of parentchild interaction therapy and triple p-positive parenting program: a review and meta-analysis. Journal of Abnormal Child Psychology, 35(3), 475-495.

Tönbül, Ö. (2019). Aile eğitimi programının annelerin çocuk yetiştirme tutumlarına etkisinin incelenmesi. Okul Psikolojik Damısmanliğ Dergisi, 2(1), 46-72.

Tuijl, C. V., \& Leseman, P. P. M. (2004). Improving mother-child interaction in low-income Turkish-Dutch families: A study of mechanisms mediating improvements resulting from participating in a home-based preschool intervention program. Infant and Child Development, 13, 323-340.

Türk Dil Kurumu (2020). https://sozluk.gov.tr/ adresinden alınmıştır.

Uykan, E., \& Akkaynak M. (2019). Ebeveyn tutumları ile çocukların öz düzenlemeleri arasındaki ilişkinin incelenmesi. Akademik Tarih ve Düs̈̈nce Dergisi, 6(3), 1620-1644. 
Yavuzer, H. (2019a). Çocuğunuzun ilk 6 ynl. İstanbul: Remzi Kitabevi.

Yavuzer, H. (2019b). Ana-baba okulu. İstanbul: Remzi Kitabevi.

Yavuzer, H. (2016). Cocuk psikolojisi. İstanbul: Remzi Kitabevi.

Yeşil, R. (2004). İnsan hakları ve demokrasi eğitiminde yöntem. Kırşehir Eğitim Fakültesi Dergisi, 5(1), $35-41$.

Yilmaz-Bolat, E. (2011). Anne baba eğitiminin beș-altı yas çocuğa sabip anne babalarn çocuk yetiştirme tutum ve davramıslarna etkisinin incelenmesi (Yayınlanmamış doktora tezi). Ankara Üniversitesi, Ankara.

Yllmaz-Bolat, E. (2017). Okul Öncesi Öğretmenlerinin OBADER Hakkındaki Görüşleri. International Periodical for the Languages, Literature and History of Turkish or Turkic, 12(29), 603616.

Yörükoğlu, A. (2010). Çocuk ruh sağhlğ. İstanbul: Özgür Yayıncilık. 